\title{
Patients' beliefs regarding informed consent for low-risk pragmatic trials
}

\author{
Rafael Dal-Ré $e^{1,2,6^{*}}$, Antonio J. Carcas ${ }^{3}$, Xavier Carné $^{2,4}$ and David Wendler ${ }^{5}$
}

\begin{abstract}
Background: The requirement to obtain written informed consent may undermine the potential of pragmatic randomized clinical trials (pRCTs) to improve evidence-based care. This requirement could compromise trials statistical power or even force it to close them down prematurely. However, recent data from the U.S. and Spain suggest that a majority of the public endorses written consent for low-risk pRCTs. The present manuscript assesses whether this view is shared by patients.

Methods: This was a cross-sectional, probability-based survey, with a $2 \times 2$ factorial design, assessing support for written informed consent versus verbal consent or general notification for two low-risk pRCTs in hypertension, one comparing 2 drugs with similar risk/benefit profiles and the other comparing the same drug being taken in the morning or at night. This web-based survey was conducted in May 2016. Two-thousand and eight adults who were representative of the Spanish population participated in the survey (response rate: 61\%). Of these 2008 respondents, 338 indicated that they had been diagnosed with hypertension and were being treated with prescription medicines for this condition at the time of responding to the survey. The primary outcome measures were respondents' personal preference and recommendation to a research ethics committee regarding the use of written informed consent versus verbal consent or general notification.

Results: Overall, 74\% of the 338 patient respondents endorsed written consent. In both scenarios, general notification received significantly more support (30.6\%-44.7\%) than verbal consent (13.3\%-17.6\%). $43 \%$ of respondents preferred and/or recommended general notification rather than written consent.
\end{abstract}

Conclusions: As in the survey of the general public, more patients endorsed written consent than the alternative option. However, two factors suggest that a different approach to written consent should be investigated for lowrisk pRCTs: a) a substantial minority of respondents supported general notification, b) data from the US have shown that most patients who prefer written consent are willing to forego it if obtaining written consent makes the trial too difficult to be conducted; and c) 2016 CIOMS guidelines endorse waivers of consent when the trial fulfills specific conditions. Surveys in other EU countries are needed to assess what patients believe towards pRCTs. If similar results to that reported in this study are found, it is foreseeable that with educational efforts, general notification could be an acceptable and widespread approach to the conduct of low-risk pRCTs.

Keywords: Survey, Low-risk pragmatic trials, Written informed consent, Verbal informed consent, General notification, Clinical trials regulation, Low-intervention clinical trials

\footnotetext{
*Correspondence: rfdalre@gmail.com

${ }^{1}$ Clinical Research, BUC (Biosciences UAM+CSIC) Program, International

Campus of Excellence, Universidad Autónoma de Madrid, Ciudad

Universitaria de Cantoblanco, Einstein 3, 28049 Madrid, Spain

${ }^{2}$ Chair on Bioethics "Grifols Foundation", University of Vic - Central University

of Catalonia, Miquel Martí i Pol 1, Campus Miramarges, E-08500, Vic,

Barcelona, Spain

Full list of author information is available at the end of the article
}

(c) The Author(s). 2017 Open Access This article is distributed under the terms of the Creative Commons Attribution 4.0 International License (http://creativecommons.org/licenses/by/4.0/), which permits unrestricted use, distribution, and reproduction in any medium, provided you give appropriate credit to the original author(s) and the source, provide a link to the Creative Commons license, and indicate if changes were made. The Creative Commons Public Domain Dedication waiver (http://creativecommons.org/publicdomain/zero/1.0/) applies to the data made available in this article, unless otherwise stated. 


\section{Background}

Recruiting a sufficient number of participants is a common problem for clinical trials. Insufficient recruitment can reduce statistical power, waste resources, increase costs and even result in the premature termination of a trial [1-3]. Acknowledging that appropriately informing potential trial participants is a key ethical principle in clinical research, seeking written informed consent could jeopardize the conduct of clinical trials. In response, a number of studies have assessed if modifications to the consent form and/or the consent process could ease participants' recruitment [4]. On the other hand, there is scarce empirical evidence of what type of information potential research participants want to know about the study: for instance, only $39 \%$ and $76 \%$ of potential participants wanted to be told about voluntariness and the purpose of the study, respectively [5].

Currently, in both the US and EU clinical trials regulations, and for all types of trials, except for clusterrandomized trials, written informed consent is asked from all participants. This requirement creates huge challenges to many pragmatic randomized controlled trials (pRCTs) preventing the appropriate conduct of many of them due to insufficient or biased recruitment [6]. Research ethics committees (RECs) could adapt current informed consent requirements to the specific needs of the research, as was the case in two pRCTs conducted in the UK with commonly prescribed medications where short (2-page) participants information sheets where used to inform potential participants [7]. However, with current regulations, RECs could never change to a verbal consent, or waived participant's consent in the conduct of pRCTs assessing the comparative effectiveness of commercially available medications. These two alternatives to written informed consent (verbal consent or general notification, i.e., a non-specific informed consent approach), however, have been shown to be supported by substantial minorities of the general public in the US and Spain when being asked on hypothetical low-risk pRCTs with commonly prescribed drugs $[8,9]$. It is important to understand whether having a chronic condition might influence individual views on written informed consent for low-risk pRCTs, of special interest since this type of trial will be frequently conducted for the assessment of commonly prescribed drugs.

\section{Methods}

Two thousand and eight adults participated in a survey conducted in Spain in May 2016, that replicated a previous survey that was conducted in the US [8]. The Spanish survey was administered to individuals belonging to Netquest (GfK group) panel (https://www.netquest.com/es/ home/encuestas-online-investigacion). This panel comprises almost 200.000 people. Adult Spaniards with internet access are invited to join ('single-use' invitation) with the goal of ensuring a representative sample of the non-institutionalized civilian Spanish population. This was a probability-based online panel -except for the oldest ( $\geq 75$ years) age group which is less represented than in the general population. The design, conduct and results of the survey have been explained in detail elsewhere [9].

The survey used a cross-sectional, $2 \times 2$ factorial design (Table 1). The survey started by explaining a hypothetical hospital in which all patients were informed through letters, brochures and posters on the simultaneous provision of care and the conduct of research (Additional file 1). Two hypothetical scenarios were assessed: two low-risk pRCTs in hypertension, comparison of 2 drugs with similar risk/benefit ratio or taking the same drug in the morning or at night. Each scenario had two routes: written consent vs verbal consent; written consent vs general notification. Each respondent was randomized to one of the 4 routes.

In the hypothetical scenarios presented to respondents, the primary outcome measures were the respondent's recommendation to the REC ("If you were to give advice to the REC, would you recommend written consent or general notification/verbal consent?") and the respondent's preference ("If you were a patient in this hospital, which would you personally prefer, written consent or general notification/verbal consent?"). Responses to both questions were 'definitely' or 'probably' for both written consent and the alternative option.

Respondents were asked to evaluate the trial by indicating whether they agree, using a 7-point scale ( 1 = strongly disagree, 7 = strongly agree), with the following three statements: a) "It is valuable to study whether one treatment option is more effective than the other for treating high blood pressure"; b) "Patients who participate in the randomized trial face greater risks than patients who receive usual care"; and c) "Patients who participate in the randomized trial are more likely to improve (lower) their high blood pressure than patients who receive usual care".

Since both of the theoretical pRCTs involved hypertension, participants were asked to report on whether they have been diagnosed with hypertension and whether they were receiving treatment with prescription medications. This article reports on the results obtained in the 338 respondents who indicated that they had been diagnosed with hypertension and were being treated at the time of responding to the survey.

\section{Statistical analysis}

Recommendations to the REC and personal preferences for written consent or the alternative approach were dichotomized. Logistic regression models were used to assess whether the pRCT scenario and alternative consent/ 
Table 1 Experimental design of the survey (Modified from Nayak et al. [8])

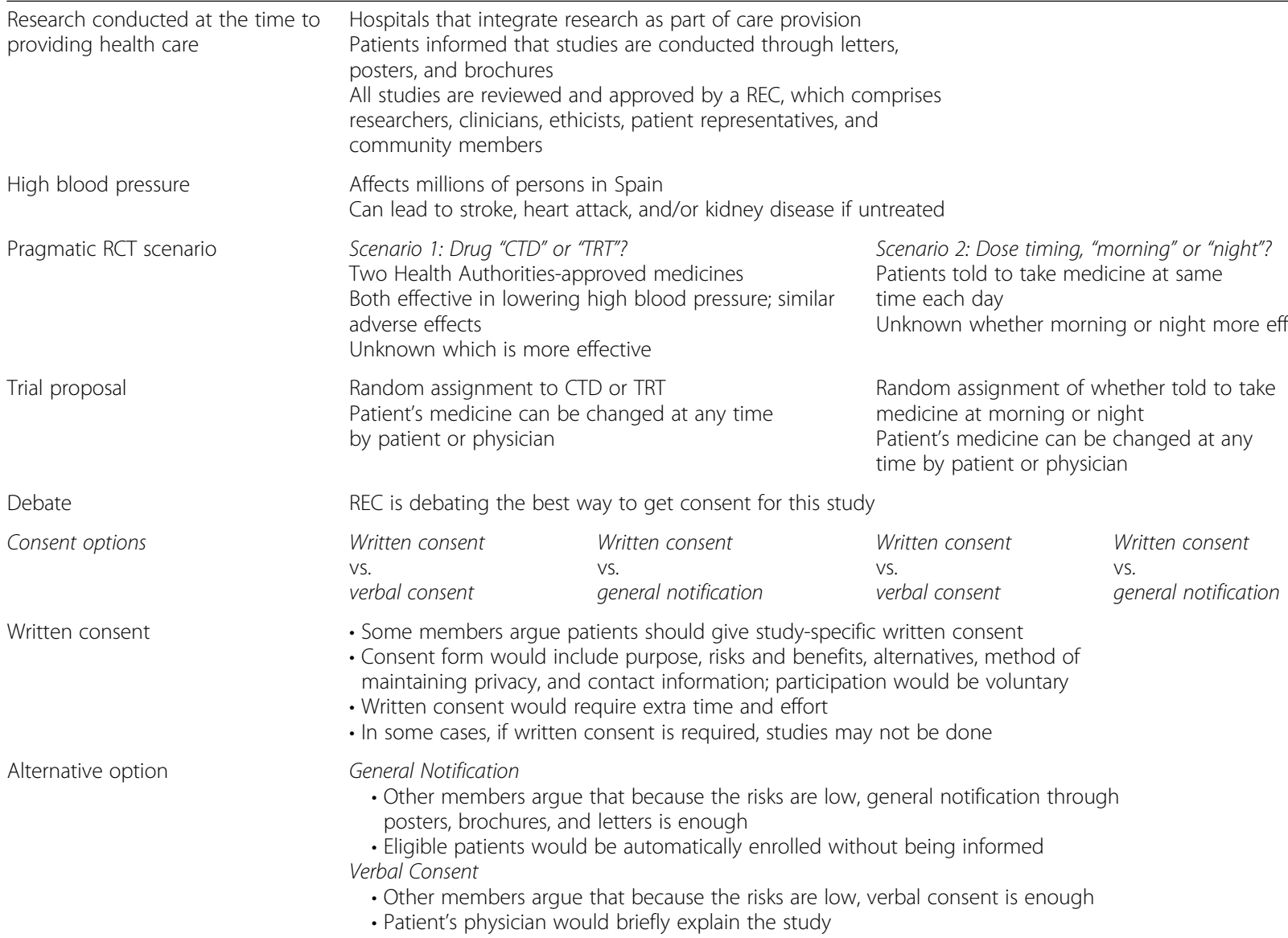

High blood pressure

Pragmatic RCT scenario

Trial proposal

Debate

Consent options

Written consent

Alternative option

Affects millions of persons in Spain

Can lead to stroke, heart attack, and/or kidney disease if untreated

Scenario 1: Drug "CTD" or "TRT"?

Two Health Authorities-approved medicines

Both effective in lowering high blood pressure; similar adverse effects

Unknown which is more effective

Random assignment to CTD or TRT
Patient's medicine can be changed at any time
by patient or physician

time each day medicine at morning or night time by patient or physician

REC is debating the best way to get consent for this study

$\begin{array}{llll}\text { Written consent } & \text { Written consent } & \text { Written consent } & \text { Written consent } \\ \text { vs. } & \text { vs. } & \text { vs. } & \text { vs. } \\ \text { verbal consent } & \text { general notification } & \text { verbal consent } & \text { general notification }\end{array}$

- Some members argue patients should give study-specific written consent

- Consent form would include purpose, risks and benefits, alternatives, method of

maintaining privacy, and contact information; participation would be voluntary

- Written consent would require extra time and effort

- In some cases, if written consent is required, studies may not be done

General Notification

- Other members argue that because the risks are low, general notification through

posters, brochures, and letters is enough

- Eligible patients would be automatically enrolled without being informed

Verbal Consent

- Other members argue that because the risks are low, verbal consent is enough

- Patient's physician would briefly explain the study

Scenario 2: Dose timing, "morning" or "night"?

Patients told to take medicine at same

Unknown whether morning or night more effective

Random assignment of whether told to take

Patient's medicine can be changed at any

Shows the $2 \times 2$ factorial design and information presented to respondents. Half received a drug RCT scenario comparing 2 first-line drugs; the others received a dose-timing RCT scenario comparing morning vs. night dosing. Half of participants in each group chose between written consent and general notification; the rest chose between written consent and verbal consent. CTD chlorthalidone, RCT randomized, controlled trial; REC Research ethics committee, TRT hydrochlorothiazide

notification option were associated with respondents' recommendations and personal preferences. The models included main effects for the research scenario (drug pRCT vs. dose-timing pRCT) and the alternative option (general notification; verbal consent), as well as the interaction of the 2 factors. To evaluate the association between respondents' perceptions of the study's value, risk, and benefit and support for the alternative option, the Pearson chi-square test of independence corrected for bootstrap was used.

All analyses were conducted in IBM SPSS statistics, version 21. According to final sample distribution, poststratification weights were not used. Statistical significance was defined as a $P$ value less than 0.05 , and all tests were 2 -sided.

\section{Results}

The survey was forwarded to 3298 panel members and started by 2243 , of which 45 dropped out before they were randomized to one of the two pRCTs scenarios. After randomization, 179 were excluded for nonresponses to one of the two alternative options (written consent vs general notification or written consent vs verbal consent). Finally, 11 individuals were excluded for not responding to both primary outcomes (recommendation to the REC and personal preference), leaving 2008 panelists completers (response rate: 60.9\%). The 338 respondents who indicated that they had been diagnosed with hypertension and were being treated with prescription medicines for this condition at the time of the survey (Fig. 1), were almost evenly distributed into the 4 groups and did not show statistically significant differences in any of the assessed characteristics (Table 2). Some 35\% of these 338 respondents were $\geq 65$ years old, quite different from the Spanish hypertensive population, of which $49 \%$ belong to this age group [10].

Recommendations to the REC and personal preferences

Overall, $74.3 \%$ of all the respondents would definitely or probably recommend use of written consent to the REC (Fig. 2a). In the drug pRCT, $31.8 \%$ would recommend general notification, whereas $17.6 \%$ would recommend 


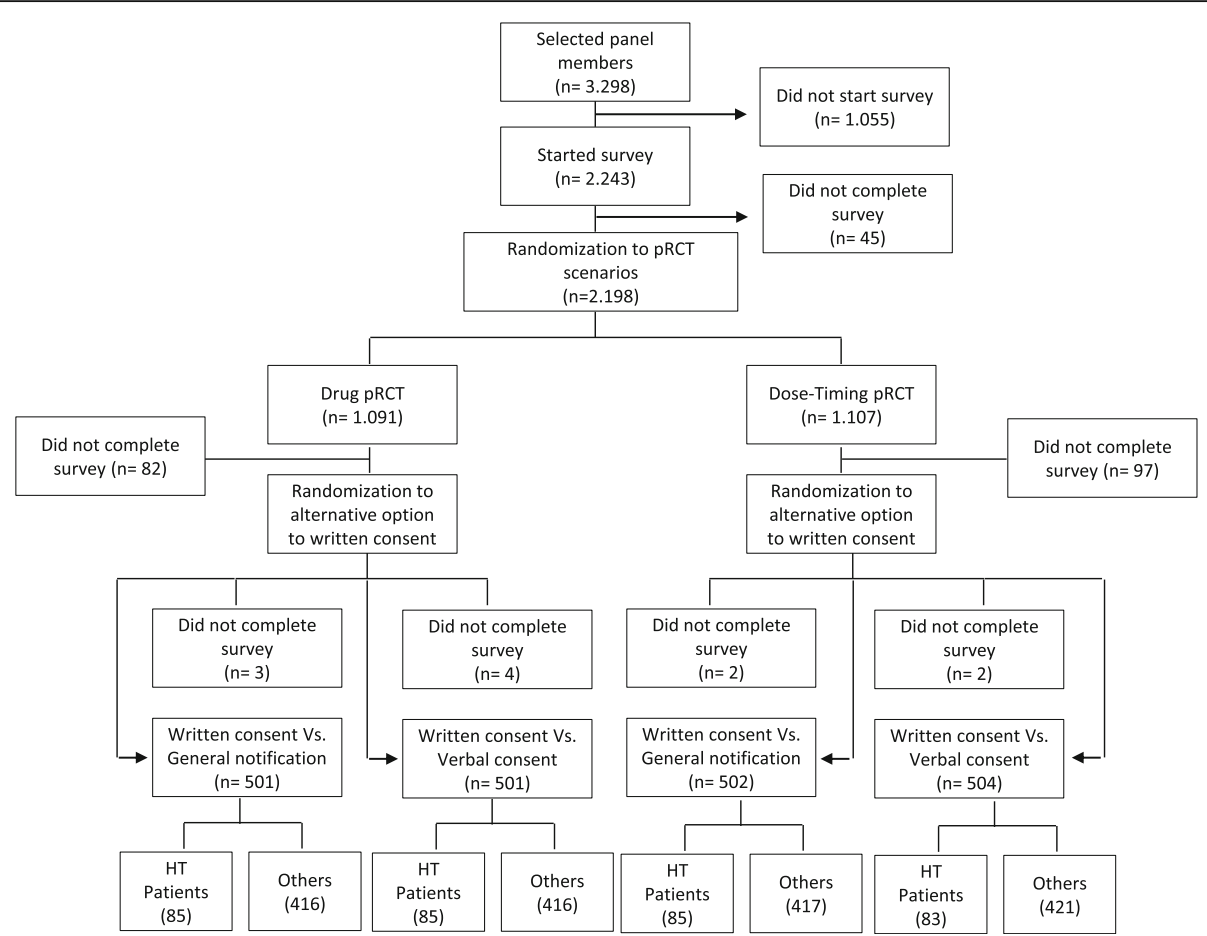

Fig. 1 Study flow diagram. HT: hypertensive

verbal consent. In the dose-timing pRCT, $40.0 \%$ would recommend general notification, whereas $13.3 \%$ would recommend verbal consent instead of written consent.

Overall, $74 \%$ of all respondents would definitely or probably prefer the use of written consent (Fig. 2b). In the drug pRCT, $30.6 \%$ prefer general notification, whereas $15.3 \%$ prefer verbal consent. In the dose-timing pRCT, $44.7 \%$ prefer general notification, whereas 13.3\% prefer verbal consent instead of written consent. Fig. 3 shows respondents' recommendations to the REC and their personal preferences.

Considering only those 170 respondents who were presented with the option of written consent or general notification in the drug $\mathrm{pRCT}$ and the dose-timing pRCT scenarios, $42.9 \%$ preferred and/or recommended general notification to the REC. Among the 168 respondents who were presented with the option of verbal consent or written consent, $16.1 \%$ preferred and/or recommended verbal consent.

Responses to the 2 items were consistent across the groups, with most (from $87.1 \%$ to $100 \%$ ) having the same recommendation and personal preference (Table 3). In the dose-timing pRCT consistency is statistically significantly greater $(100 \%$ vs $88.3 \% ; p=0.001)$ when verbal consent is the alternative option instead of general notification. In both scenarios (drug RCT and dose-timing $\mathrm{RCT}$ ) the percentage of respondents who preferred and/ or recommended the alternative option is statistically significantly higher when the alternative is general notification rather than verbal consent $(37.6 \%$ vs $18.8 \%$, $p=0.005$, in drug RCT; and $48.2 \%$ vs $17.3 \%, p<0.001$ in dose-timing RCT). The percentage of respondents who preferred the alternative option was not statistically significantly different in any of the 4 groups compared with the percentage of respondents that would recommend the alternative option to the REC (Fig. 3).

A logistic regression model was used to test the effect of the experimental design of the survey on recommendations for using the alternative option over written consent. As mentioned above, the main effect is the alternative option presented: in both scenarios, drug pRCT and dose-timing pRCT, a statistically significant higher percentage of respondents recommended and preferred the alternative option of general notification rather than verbal consent $(p<0.001)$. The likelihood to recommend general notification to the REC is close to 4 times higher than verbal consent in the dose-timing pRCT scenario $(\mathrm{OR}=3.712$; $p<0.001)$ and almost 3 times higher in the drug pRCT scenario $(\mathrm{OR}=2.910, p<0.001)$. Similarly, the likelihood of preferring general notification is close to 4 times higher than verbal consent in the dose-timing pRCT scenario $(\mathrm{OR}=3.974 ; p<0.001)$ and almost 3 times higher in the drug pRCT scenario $(0 \mathrm{R}=2.724, p<0.001)$. A table with the logistic regression analysis is shown in Additional file 2.

\section{Views of pragmatic RCT scenarios}

A large majority of respondents agreed that the described trial was valuable, with no statistically significant 
Table 2 Characteristics of the 338 hypertensive respondents by scenario and group

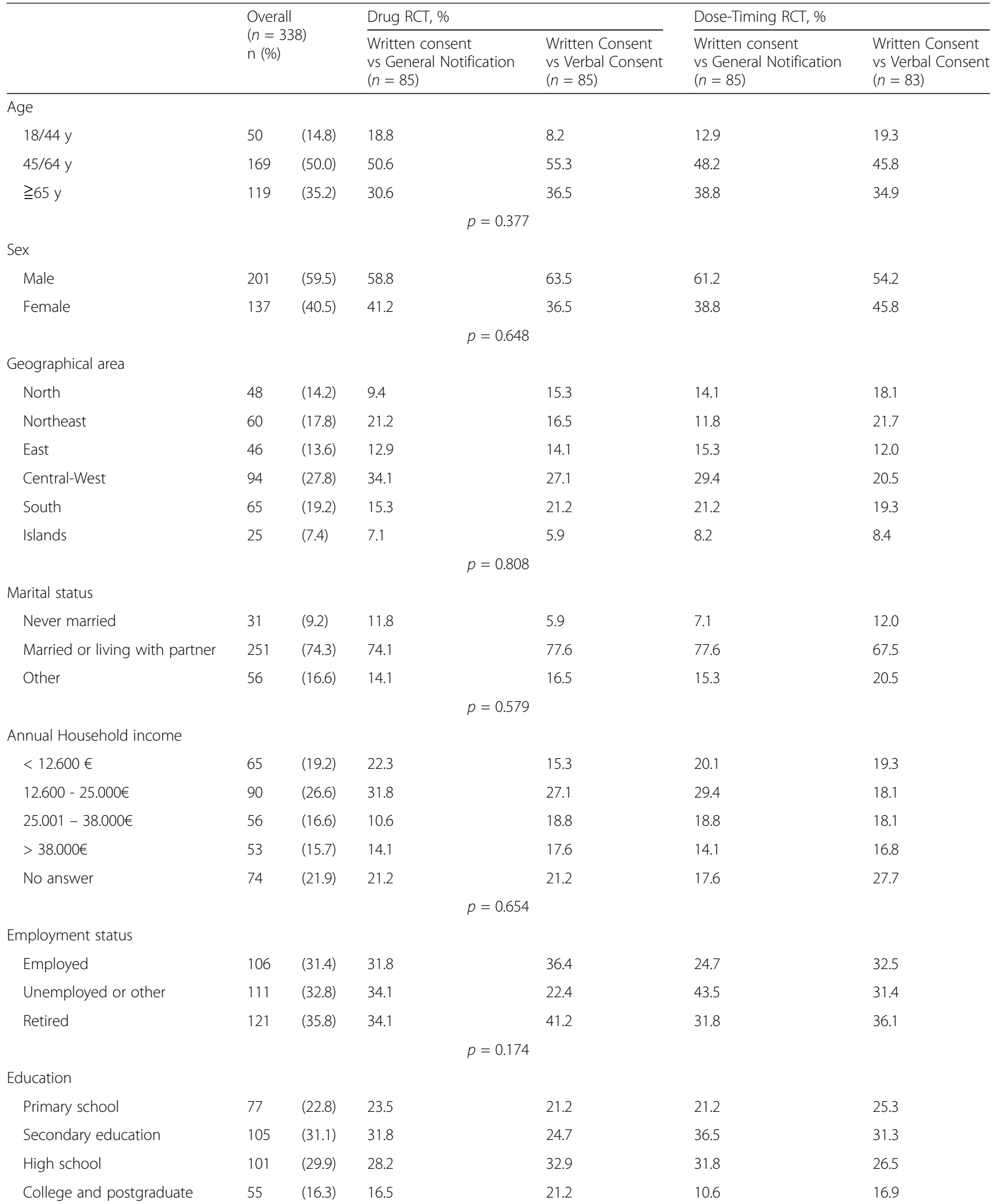


Table 2 Characteristics of the 338 hypertensive respondents by scenario and group (Continued)

\begin{tabular}{|c|c|c|c|c|c|c|}
\hline \multicolumn{7}{|c|}{$p=0.731$} \\
\hline \multicolumn{7}{|c|}{ Religious attendance } \\
\hline Regularly & 59 & $(17.5)$ & 18.8 & 17.6 & 14.1 & 19.3 \\
\hline Rarely & 59 & $(17.5)$ & 23.5 & 16.5 & 16.5 & 13.3 \\
\hline Never & 177 & $(52.4)$ & 44.7 & 57.6 & 55.3 & 51.8 \\
\hline No answer & 43 & $(12.7)$ & 12.9 & 8.2 & 14.1 & 15.7 \\
\hline \multicolumn{7}{|c|}{$p=0.625$} \\
\hline \multicolumn{7}{|l|}{ Ideology } \\
\hline $1-2$ Left & 63 & (18.6) & 17.6 & 20.0 & 14.1 & 22.8 \\
\hline 3 & 67 & (19.8) & 21.3 & 20.0 & 17.7 & 20.5 \\
\hline 4 Moderate & 105 & (31.1) & 29.4 & 37.6 & 34.1 & 22.9 \\
\hline 5-6-7 Right & 57 & (16.9) & 14.1 & 15.3 & 17.6 & 20.5 \\
\hline No answer & 46 & (13.6) & 17.6 & 7.1 & 16.5 & 13.3 \\
\hline \multicolumn{7}{|c|}{$p=0.541$} \\
\hline
\end{tabular}

differences between the two scenarios: $90.6 \%$ in drug pRCT, 93.5\% in dose-timing pRCT (Table 4). Some 36\% and $48 \%$ of respondents in both scenarios believed that trial participants would face greater risks and greater potential benefit, respectively, than those receiving usual care.

\section{Discussion}

The majority (74\%) of patients participating in this survey endorsed written informed consent for low-risk pRCTs. This finding is similar to the results found in the general population [9] (77\% supported written consent) and suggests that being affected by the condition under study does not affect respondents' beliefs regarding the need to obtain written informed consent for low-risk pRCTs. In particular, patients were not more willing to accept an alternative to written informed consent compared to the general population.

The responses observed in the Spanish general population [9] and in the patients were rather similar, although a few slightly differences were noted. Although the percentages of respondents who recommended and/or preferred the alternative option were similar in the general population (40\%) and the hypertensive patients (43\%), the patients were more likely to have consistent responses between their preference and their recommendation to the REC (22.2\% versus $17.7 \%)$ [9]. Similarly, the hypertensive patients had somewhat worse understanding of the perceived risks and benefits of being enrolled in a clinical trial: $36 \%$ of hypertensives (vs 32\% in the general population) thought participating in a RCT poses more risks than usual care, whereas $48 \%$ of hypertensive respondents (vs $43 \%$ ) believed participating in a $\mathrm{RCT}$ offers greater potential benefits. The different age distribution (hypertensive patients sample being much older) might help to explain these two differences; this could be object of a future study.

These present results are somewhat surprising. Limited available data on what patients (120 respondents of an online survey) believed regarding consent to participate in a hypertension drug low-risk pRCT, found that only $38 \%$ of respondents endorsed written consent and $42 \%$ endorsed verbal consent. In contrast, $21 \%$ indicated that broad notification was sufficient (16\%) or no notification (5\%) was needed [11]. The relatively high percentage of respondents in our survey supporting general notification (43\%) versus written consent may be explained, in part, by the high trust the Spanish population has in physicians (95\%) and in the universal public National Health Service (75\%) [12], where the hypothetical scenarios were placed.

To the best of our knowledge, this is the first study conducted in any EU Member State assessing the opinion of patients with regards to written informed consent for lowrisk pRCTs. However, it has several important limitations. First, as with the parent survey [9], the response rate was $61 \%$, and it is not possible to determine whether nonrespondents might differ from respondents; in addition, framing effects and the use of hypothetical scenarios might have influenced respondents' attitudes -notably, the hypothetical scenarios, involving pRCTs conducted in clinical settings, likely were unfamiliar to many respondents. Second, the age distribution of this study sample is quite different from that of the Spanish hypertensive population: whereas $49 \%$ of hypertensive patients in Spain are $\geq 65$ years old [9], in this study only $35 \%$ were in this age group. Third, we relied on self-report for whether the respondents were diagnosed with hypertension and whether they were taking medication. Finally, the study 


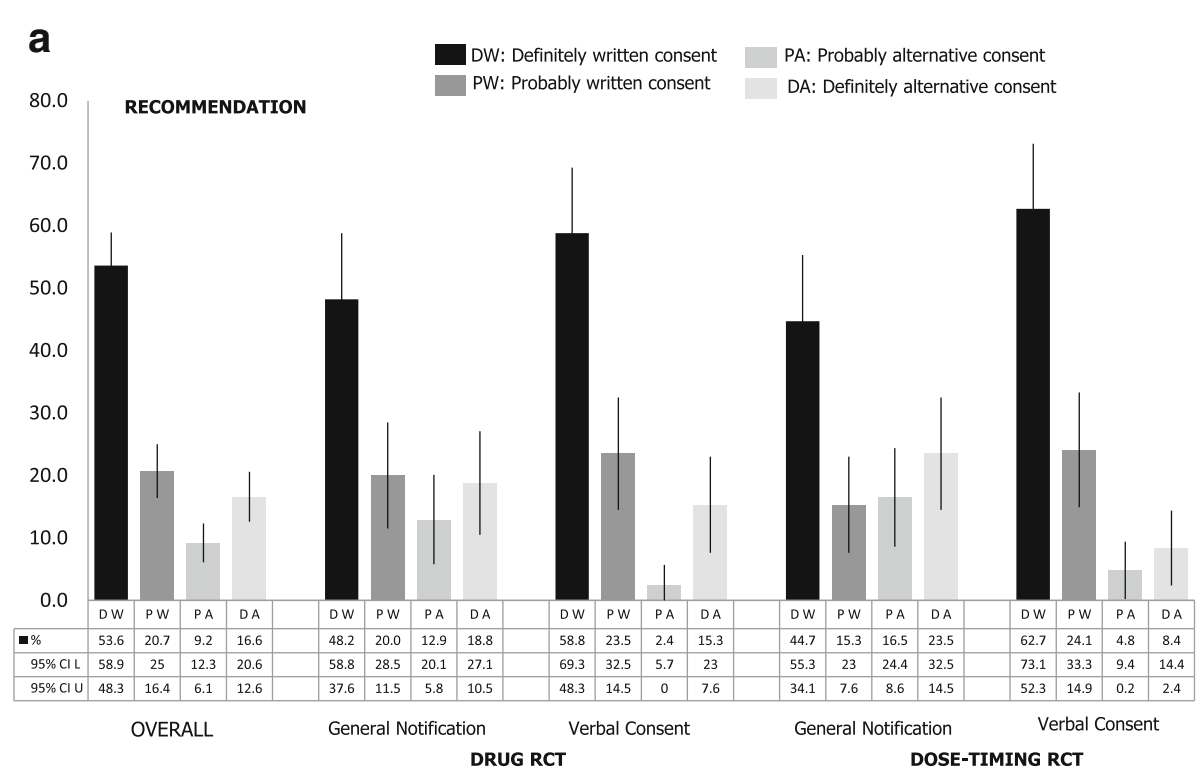

b

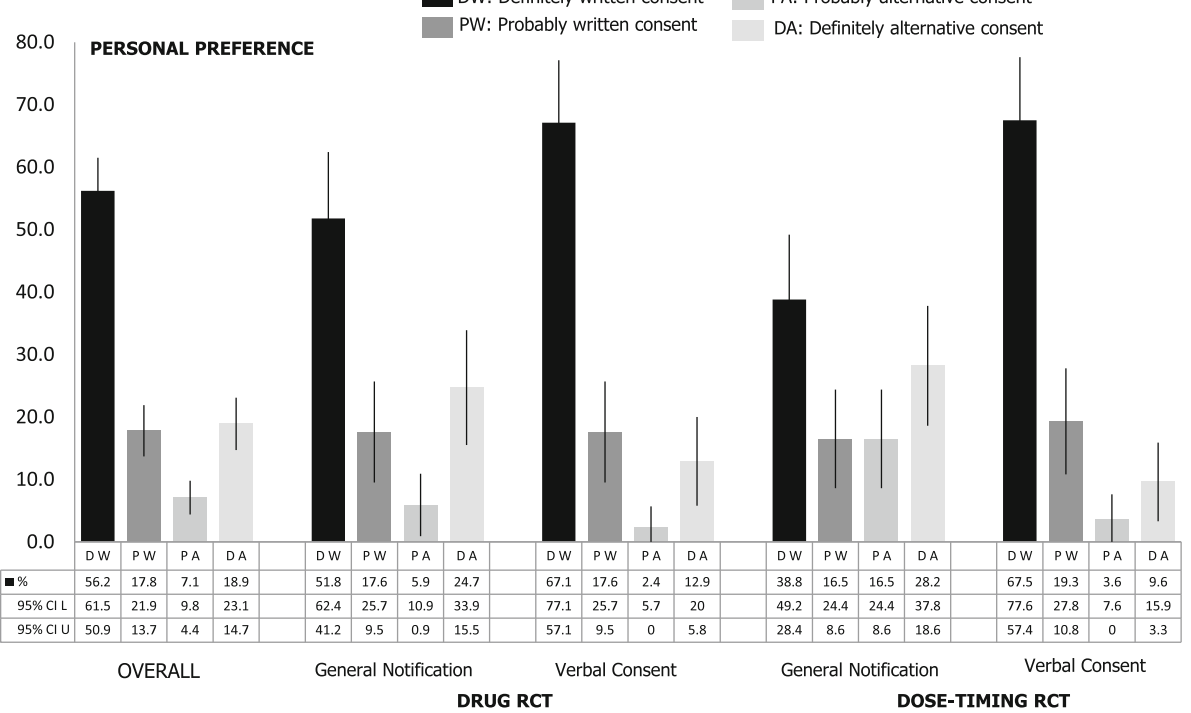

Fig. 2 Recommendations to the research ethics committee (top) and personal preferences (bottom) for written consent and the alternative option. 2a.-Recommendation ro research ethics committee. 2b.-Personal preference. Cl: Confidence interval; L: Lower limit; U. Upper limit; RCT: Randomized controlled trial

design did not allow us to assess directly which alternative method (verbal consent or general notification) respondents would prefer or recommend.

The informed consent process is not "one size fits all" and should be tailored to context [13]. In some cases it can even be waived. Thus, the recently issued CIOMS guidelines endorse the waiver of participant's informed consent when the three following conditions are satisfied: a) the research is not practicable without the waiver; b) the research has important value; and c) the research poses no more than minimal risk to participants; in any case, the relevant REC must approve the waiver of informed consent [14]. Many low-risk pRCTs could fulfill these three conditions since, a) requiring informed consent to participants might jeopardize its correct conduct, since it is a barrier to unselected participant recruitment [15]; b) when a trial helps policy makers determine which options to fund in National Healthcare Systems [16], the (public) value of the trial is out of question, and c) low-risk pRCTs typically pose no incremental risk (i.e., no more than minimal risk) compared to clinical care [17]. pRCTs that would easily fulfill these three criteria are those conducted with commercially available medications and using routing electronic 


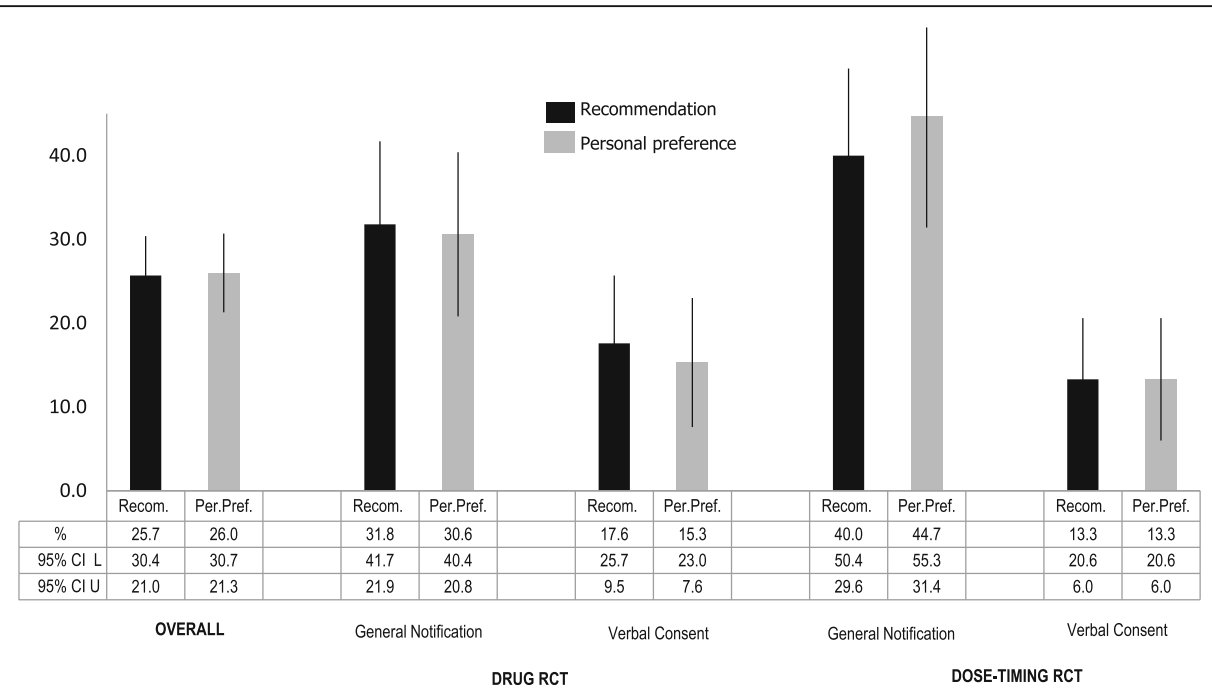

Fig. 3 Support for alternative options to written consent. Cl: Confidence interval; L: Lower limit; U. Upper limit; RCT: Randomized controlled trial

health records, also known as point-of-care trials [7, 1821]. The conduct of this type of pRCTs will most likely be fostered if investigators show to RECs the fulfillment of these three conditions. However, the EU new clinical trials regulations do not take into account the possibility of a waiver of the classical written informed consent except for cluster-RCTs [22].

It seems clear that to ensure the proper conduct and recruitment of participants to low-risk pRCTs there is a need to identify new approaches to written informed consent that should end-up with the amendment of current clinical trials regulations [23].
Two different approaches have been proposed in the US when considering low-risk pRCTs when clinical research is integrated in medical care: one supports asking for patient's verbal consent to participate after explaining that randomization will decide participant's treatment [24]; whereas the other strongly believes there is no need to ask for specific consent $[25,26]$.

\section{Conclusion}

Future surveys are needed within the EU member states addressing patients' beliefs with regards to

Table 3 Cross tabulation of respondents' recommendation to the research ethics committee (REC) and personal preferences

\begin{tabular}{|c|c|c|c|c|c|}
\hline \multirow[t]{2}{*}{ Variable } & \multirow[t]{2}{*}{ Overall, \% $(n=338)$} & \multicolumn{2}{|l|}{$\begin{array}{l}\text { Drug pRCT, } \\
\%\end{array}$} & \multicolumn{2}{|l|}{$\begin{array}{l}\text { Dose-timing } p R C T, \\
\%\end{array}$} \\
\hline & & $\begin{array}{l}\text { Written consent vs } \\
\text { General notification } \\
(n=85)\end{array}$ & $\begin{array}{l}\text { Written consent vs } \\
\text { Verbal consent } \\
(n=85)\end{array}$ & $\begin{array}{l}\text { Written consent vs } \\
\text { General notification } \\
(n=85)\end{array}$ & $\begin{array}{l}\text { Written consent vs } \\
\text { Verbal consent } \\
(n=83)\end{array}$ \\
\hline $\begin{array}{l}\text { Recommended written consent, } \\
\text { preferred written consent }\end{array}$ & 70.4 & 62.4 & 81.2 & 51.8 & 86.7 \\
\hline $\begin{array}{l}\text { Recommended written consent, } \\
\text { preferred alternative option }\end{array}$ & 3.8 & 5.9 & 1.2 & 8.2 & 0.0 \\
\hline $\begin{array}{l}\text { Recommended alternative option, } \\
\text { preferred written consent }\end{array}$ & 3.6 & 7.1 & 3.5 & 3.5 & 0.0 \\
\hline \multirow{2}{*}{$\begin{array}{l}\text { Recommended alternative option, } \\
\text { preferred alternative option }\end{array}$} & 22.2 & 24.7 & 14.1 & 36.5 & 13.3 \\
\hline & & $p=0.042$ & & $p<0.001$ & \\
\hline \multirow{2}{*}{$\begin{array}{l}\text { Same personal preference and } \\
\text { recommendation to the REC } \\
\text { (Consistent responses) }\end{array}$} & 92.6 & 87.1 & 95.3 & 88.3 & 100.0 \\
\hline & & $p=0.051$ & & $p=0.001$ & \\
\hline \multirow{2}{*}{$\begin{array}{l}\text { Personal preference and/or } \\
\text { recommendation alternative option }\end{array}$} & 92.6 & 37.6 & 18.8 & 48.2 & 17.3 \\
\hline & & $p=0.005$ & & $p<0.001$ & \\
\hline
\end{tabular}


Table 4 Views of the hypertensive patients on statements about social value, risk and benefit of the pragmatic randomized controlled trial (pRCT) scenarios

\begin{tabular}{|c|c|c|c|c|c|}
\hline \multirow[t]{2}{*}{ Statement } & \multirow[t]{2}{*}{ Scenario } & \multicolumn{3}{|c|}{ Response, \% } & \multirow[t]{2}{*}{$P$ value } \\
\hline & & Disagree & Neutral & Agree & \\
\hline $\begin{array}{l}\text { It is valuable to study whether one treatment option is more } \\
\text { effective than the other for treating high blood pressure }\end{array}$ & $\begin{array}{l}\text { Drug } p R C T^{a} \\
\text { Dose-timing } p R C T^{b}\end{array}$ & $\begin{array}{l}3.5 \\
1.8\end{array}$ & $\begin{array}{l}5.9 \\
4.8\end{array}$ & $\begin{array}{l}90.6 \\
93.5\end{array}$ & 0.538 \\
\hline $\begin{array}{l}\text { Patients who participate in the randomized trial face greater } \\
\text { risks than patients who receive usual care }\end{array}$ & $\begin{array}{l}\text { Drug } \mathrm{pRCT}^{\mathrm{a}} \\
\text { Dose-timing } \mathrm{pRCT}{ }^{\mathrm{b}}\end{array}$ & $\begin{array}{l}31.8 \\
40.5\end{array}$ & $\begin{array}{l}27.6 \\
25.6\end{array}$ & $\begin{array}{l}40.6 \\
33.9\end{array}$ & 0.233 \\
\hline $\begin{array}{l}\text { Patients who participate in the randomized trial are more } \\
\text { likely to improve (lower) their high blood pressure than patients } \\
\text { who receive usual care. }\end{array}$ & $\begin{array}{l}\text { Drug } \mathrm{pRCT}^{\mathrm{a}} \\
\text { Dose-timing } \mathrm{pRCT}\end{array}$ & $\begin{array}{l}17.6 \\
14.9\end{array}$ & $\begin{array}{l}36.5 \\
35.7\end{array}$ & $\begin{array}{l}45.9 \\
49.4\end{array}$ & 0.729 \\
\hline
\end{tabular}

${ }^{a} n=170$

$\mathrm{b}_{n}=168$

informed consent in low-risk pRCTs and, very importantly, to know if their beliefs would change if they were aware that the trial could not be conducted as expected if participants' written informed consent is sought. This is relevant since a majority of both US patients [11] and public [27] endorsing written or verbal consent for low-risk pRCTs changed their minds if consent poses huge difficulties to the conduct of such trials and would accept general or no notification. Now that the conduct of low-risk pRCTs with no participant's consent could be ethically acceptable in certain circumstances [14], it would be appropriate to know what EU patients believe on this subject so regulators could know what the society they serve is expecting. However, it should be acknowledged that most (if not all) RECs in the EU will reject on legal grounds the approval of a low-risk pRCT asking for a waiver of participants' consent until EU clinical trials regulation is appropriately amended.

\section{Additional files}

Additional file 1: Survey Questionnaire (DOCX $33 \mathrm{~kb}$ )

Additional file 2: Recommendation to research ethics committee and personal preference: written consent or alternative option. Logistic regression (DOCX $14 \mathrm{~kb}$ )

Additional file 3: Anonymous participant level data (XLSX 50 kb)

\section{Abbreviations}

CIOMS: Council for International Organizations of Medical Sciences (Geneva Switzerland); pRCT: Pragmatic randomized controlled trial; RCT: Randomized controlled trial; EU: European Union

\section{Acknowledgements}

We are grateful to the 338 anonymous respondents who participated in the survey.

\section{Funding}

This work was supported in part by the Victor Grifols i Lucas Foundation (Barcelona, Spain: http://www.fundaciogrifols.org/en/web/fundacio/home) -devoted to promote bioethics in the field of human health-, that had no role in the design of the study; analysis or interpretation of the data; preparation, review or approval of the manuscript; or the decision to submit the manuscript for publication. The opinions expressed in this article are those of the authors and may not reflect the opinions of the organizations that they work for.

Wendler is a NIH employee. The present work was funded in part by intramural research funds of the U.S. NIH Clinical Center. However, the views expressed are the authors' own. They do not represent the position or policy of the $\mathrm{NIH}$, the DHHS, or the U.S. government.

\section{Availability of data and materials}

The data set (anonymous participant level data) of this article is included within the article as Additional file 3.

\section{Authors' contributions}

RDR conceived the idea and wrote the first draft of the manuscript. AJC, XC and DW made substantial revisions for intellectual content. All authors approved the final version of the manuscript and are accountable for all aspects included in it.

\section{Ethics approval and consent to participate}

The study protocol was reviewed by the research ethics committee of the Universidad Autónoma de Madrid (Madrid, Spain), which granted approval on March 14, 2016 (Ref. \# CEl-70-1265). All anonymous participants consented to participate by responding to the survey.

\section{Consent for publication}

NA

\section{Competing interests}

None to declare except for financial support mentioned in "Funding". Dal-Ré and Carné are trustees of the Victor Grifols i Lucas Foundation. The authors declare that they have no competing interest

\section{Publisher's Note}

Springer Nature remains neutral with regard to jurisdictional claims in published maps and institutional affiliations.

\section{Author details}

${ }^{1}$ Clinical Research, BUC (Biosciences UAM+CSIC) Program, International Campus of Excellence, Universidad Autónoma de Madrid, Ciudad Universitaria de Cantoblanco, Einstein 3, 28049 Madrid, Spain. ${ }^{2}$ Chair on Bioethics "Grifols Foundation", University of Vic - Central University of Catalonia, Miquel Martí i Pol 1, Campus Miramarges, E-08500, Vic, Barcelona, Spain. ${ }^{3}$ Clinical Pharmacology Department, La Paz University Hospital, IdiPaz, School of Medicine, Universidad Autónoma de Madrid, Paseo de la Castellana 261, 28046 Madrid, Spain. ${ }^{4}$ Clinical Pharmacology Department, Clínic Hospital, August Pi i Sunyer Biomedical Research Institute (IDIBAPS), Clinical Fundamentals Department, Universidad de Barcelona, Carrer de Villarroel 170, 08036 Barcelona, Spain. ${ }^{5}$ Section on Research Ethics, Department of Bioethics, NIH Clinical Center, 10 Center Dr, Bethesda, MD 20814, USA. ${ }^{6}$ Epidemiology Unit, Health Research Institute-Fundación Jiménez Díaz University Hospital, Universidad Autónoma de Madrid, Avda. Reyes Católicos 2, E-28040 Madrid, Spain. 
Received: 30 June 2017 Accepted: 10 September 2017

Published online: 18 September 2017

\section{References}

1. McDonald AM, Knight RC, Campbell MK, Entwistle VA, Grant AM, Cook JA, et al. What influences recruitment to randomised controlled trials? A review of trials funded by two UK funding agencies. Trials. 2006;7:9.

2. Damen L, van Agt F, de Boo T, Huysmans F. Terminating clinical trials without sufficient subjects. J Med Ethics. 2012;38:413-6.

3. Kasenda B, von Elm E, You J, Blümle A, Tomonaga Y, Saccilotto R, et al. Prevalence, characteristics, and publication of discontinued randomized trials. JAMA. 2014;311:1045-51.

4. Treweek S, Mitchell E, PitkethlyM CJ, KjeldstrømM JM, et al. Strategies to improve recruitment to randomised controlled trials. Cochrane Database System Rev. 2010;4:MR000013.

5. Kirkby HM, Calvert M, Draper H, Keeley T, Wilson S. What potential research participants want to know about research: a systematic review. BMJ Open. 2012;2:e000509.

6. Sugarman J, Califf RM. Ethics and regulatory complexities for pragmatic clinical trials. JAMA. 2014;311:2381-2.

7. Staa TP, Goldacre B, Gulliford M, Cassell J, Pirmohamed M, Taweel A, et al. Pragmatic randomised trials using routine electronic health records: putting them to the test. BMJ. 2012;344:e55.

8. Nayak RK, Wendler D, Miller FG, Kim SY. Pragmatic randomized trials without standard informed consent?: a National Survey. Ann Intern Med. 2015:163:356-64.

9. Dal-Ré R, Carcas A, Carné X, Wendler D. Public preferences on written informed consent for low-risk pragmatic clinical trials in Spain. Br J Clin Pharmacol. 2017;83:1921-31.

10. Banegas JR, Graciani A, de la Cruz-Troca JJ, León-Muñoz LM, GuallarCastillón P, Coca A, et al. Achievement of cardiometabolic goals in aware hypertensive patients in Spain: a nationwide population-based study. Hypertension. 2012;60:-898, 905.

11. Kraft SA, Cho MK, Constantine M, Lee SS, Kelley M, Korngiebel D, et al. A comparison of institutional review board professionals' and patients' views on consent for research on medical practices. Clin Trials. 2016;13:555-65.

12. Ferrandiz JP. La confianza institucional remonta en 2016, salvo la universidad, la banca, los sindicatos y las grandes empresas. [Institutional trust remounts in 2016, with the exception of universities, banks, trade unions and large corporations] Metroscopia. http://metroscopia.org/sistemaeducativo-sindicatos-bancos-y-grandes-empresas-pierden-la-batalla-de-laconfianza-de-los-espanoles/. Accessed 13 Sept 2017.

13. Grady C. The changing face of informed consent. N Engl J Med. 2017;376:857-9.

14. Council for International Organizations of Medical Sciences (CIOMS). International Ethical Guidelines for Health-related Research involving Humans. Geneva. 2016. https:/cioms.ch/wp-content/uploads/2017/01/WEBCIOMS-EthicalGuidelines.pdf. Accessed 13 Sept 2017.

15. Ford I, Norrie J. Pragmatic Trials. N Engl J Med. 2016;375:454-63.

16. Garattini S, Jakobsen JC, Wetterslev J, Bertelé V, Banzi R, Rath A, et al. Evidence-based clinical practice: overview of threats to the validity of evidence and how to minimise them. Eur J Intern Med. 2016;32:13-21.

17. Lantos JD, Wendler D, Septimus E, Wahba S, Madigan R, Bliss G. Considerations in the evaluation and determination of minimal risk in pragmatic clinical trials. Clin Trials. 2015;12:485-93.

18. Carcas AJ, Abad Santos F, Sánchez Perruca L, Dal-Ré R. Electronic medical record in clinical trials of effectiveness of drugs integrated in clinical practice. Med Clin (Barc). 2015;145:452-7.

19. Winhusen T, Wilder C, Wexelblatt SL, Theobald J, Hall ES, Lewis D, et al. Design considerations for point-of-care clinical trials comparing methadone and buprenorphine treatment for opioid dependence in pregnancy and for neonatal abstinence syndrome. Contemp Clin Trials. 2014;39:158-65.

20. Shih MC, Turakhia M, Lai TL. Innovative designs of point-of-care comparative effectiveness trials. Contemp Clin Trials. 2015;45(Pt A):61-8.

21. -US Department of Veterans Affairs. Office of Research \& Development. Point-of-care research. http://www.research.va.gov/services/csrd/point-ofcare.cfm.

22. -Regulation (EU) No. 536/2014 of the European Parliament and of the Council of 16 of April 2014 on clinical trials on medicinal products for human use, and repealing Directive 2001/20/EC. Official Journal of the European Union L 158/1-76. 27 May 2014. http://ec.europa.eu/health/files/ eudralex/vol-1/reg_2014_536/reg_2014_536_en.pdf. Accessed 13 Sept 2017.
23. McKinney RE Jr, Beskow LM, Ford DE, Lantos JD, McCall J, Patrick-Lake B, et al. Use of altered informed consent in pragmatic clinical research. Clin Trials. 2015;12:494-502.

24. Kim SY, Miller FG. Informed consent for pragmatic trials-the integrated consent model. N Engl J Med. 2014;370:769-72.

25. Faden R, Kass N, Whicher D, Stewart W, Tunis S. Ethics and informed consent for comparative effectiveness research with prospective electronic clinical data. Med Care. 2013;51(suppl 3):S53-7.

26. Faden RR, Beauchamp TL, Kass NE. Informed consent, comparative effectiveness, and learning health care. N Engl J Med. 2014;370:766-8.

27. Cho MK, Magnus D, Constantine M, Lee SS, Kelley M, Alessi S, et al. Attitudes toward risk and informed consent for research on medical practices: a cross-sectional survey. Ann Intern Med. 2015;162:690-6.

\section{Submit your next manuscript to BioMed Central and we will help you at every step:}

- We accept pre-submission inquiries

- Our selector tool helps you to find the most relevant journal

- We provide round the clock customer support

- Convenient online submission

- Thorough peer review

- Inclusion in PubMed and all major indexing services

- Maximum visibility for your research

Submit your manuscript at www.biomedcentral.com/submit
Biomed Central 